\title{
Protect the Environment and Protect Yourself from the Environment
}

\author{
Shamim Niazi ${ }^{1,2^{*}}$ iD \\ ${ }^{1}$ Department of Earth and Environmental Studies, Montclair State University, New Jersey, USA \\ ${ }^{2}$ United States Agency for International Development in Afghanistan, Afghanistan
}

Knowing the potential of a country and nation is critical for setting reasonable and analyzed vision of sustainable development for the people and their present and future generations. The natural and cultural resources of a country and people are fundamental to fostering the intergenerational equity, sustainable development and free and independent values. Natural resources are derived from the environment that includes both biotic and abiotic or renewable and non-renewable resources and these natural resources define how wealthy or poorer the country is. Cultural resources are historic and architectural sites, ruins, artifacts, sacred sites, traditional cultural properties, old structures, or places and locations of traditional cultural or religious importance to specific social or cultural groups. Both natural and cultural resources bless value to the physical environment of the country and people. Economic and sustainability opportunities in such countries exist in the form of natural and cultural tourisms.

Nature and culture are interwoven but nature determines the collective values of a culture. In other words, nature nurtures culture. The natural laws and the historical changes in cultures due to changing natural conditions define needs of the people that in turn form societal fundamental laws, traditions, religion and communication. Current development either sustainable or unsustainable is actually based on the connections that exist between nature and the people. Finding a balance between culture and nature is important to guarantee the sustainability and resilience of a society.

Human potential is derived from their culture and their environment. Culture is a collective choice of people that is either shaped by the environment or by the religious doctrine. The culture that constantly adapts itself to the changing natural and human-made environment is most likely to unlock or unleash the human potentials from within the culture and the same is true the other way around as well. A culture that has unique values, rites, norms and flexible to adapt itself to the changing natural conditions in the environment is likely to be more successful than the culture that is not flexible. Another potential of the people lies in the environmental resources and these resources are the sun, soil, air, mountains, water, wind, climate, weathers, animals, forests and so on. The environment is also collective resource of the people of which natural/ecological services are constant and identical across cultures. In fact both the environment and cultural resources are shared and collective choice of the people that shared the same culture in the same environment. The ideal solution could be to manage the environment/natural resources collectively and sustainably. However, differences in the cultures define the owners of the collective environmental resources. In fact, both the natural and cultural are priceless. This priceless nature of both the resources has stimulated unlimited thirst or desires for powers and wealth among humans in the same environment.

Natural geographies and environmental challenges, birth to exclusive human cultures. In an ideal world, one may think that peoples with rich natural resources would be able to formulate cultures that are able to adapt quickly and flourish. However, unfortunately this has not been true. External influences, such as states or humans, intervene in all areas of social and economic life. We live in a world where every person is competing for resources with every other person. Evidence suggests that resource abundant nations are less likely to experience rapid development. Rich natural resources can't determine good life for the people unless cultures are rich and people are informed and reasonable.

The growing demands and needs of a growing population challenge survival of the natural environment and everything in nature. In micro-level competition, all living things, particularly humans, fight or compete with each other for their survival. Micro level collective competition often leads to macro level competition. Yes, competitions birth to creativity or new thinking and new reasons for development. However, the desire for more and more provokes the living things to go beyond the limits of nature. The desire for more is not be-

*Corresponding author: Shamim Niazi, Department of Earth and Environmental Studies, Montclair State University, New Jersey, USA; United States Agency for International Development in Afghanistan, Afghanistan

Accepted: October 01, 2020

Published online: October 03, 2020

Citation: Niazi S (2020) Protect the Environment and Protect Yourself from the Environment. Adv Environ Stud 4(2):300-306 
cause of selfishness but because of fear of losing the chances of survival or the collective desire for the excellence of one specific group of living creatures over another. Fear brings both peace and violence. However, a great deal of literature suggests that limited natural resources and the exponential growth of humans, has led to violence and discomfort. Fear drives actions in nature and this rational behavior forms the basis of competition for limited resources in the natural environment.

Natural resources and ecosystem services are important to keep in balance and ensure survival of the living creatures on the earth. Historically, natural evolution has intact the balance between natural services and natural creatures. But in the past hundred years the understanding of nature and environment has created conflicting ideologies and knowledge among different cultures. Since supply and demand are unmatched, humans must struggle to satisfy their needs. Relations and connections between nature and the living creatures are varied and are based on individual and collective micro and macro needs. Darwin called it Natural Selection-the process in which those plants or animals that adapted better to their environment survived and those that did not adapt become extinct. However, this definition misses the broader element, which is the survival of nature itself, which is at risk. The collective thinking to maintain the natural services in natural form must become the only ideology and cry of today and future generations.

In order to ensure the continued survival of the productive environment and flourishing culture, it is important to consider the natural laws as the crucial foundation of all activities, actions, research, and development in order to establish natural connections (or ties) between humans with the nature. In other words, the connected and coordinated ecosystem requires a very well understanding of the natural laws and common believe over the natural laws across different cultures and religions. Our relationship with the environment is not reciprocal, but the relationship with our natural environment is based on our personal or collective needs for our social, economic, or political survival. For survival we satisfy our needs from the environment, but often ignore the needs of the environment. In the past until now humans have been managing environment based on their needs. The environment is not managed in accordance with the natural laws or humans have not regarded natural laws as the foundation of their development. Sustainable development is possible when the natural laws or patterns become the core principle of development. When such natural arrangements are not integrated in the development, then protection from the environmental catastrophes are must. In Naomi Klein's words [1], if we did not change our everything, climate change will change our everything. By changing our everything, Klein means changing the dominant economic and ideological model of free-market capitalization, carbon-intensive lifestyles and deeply-engrained cultural assumptions that humans can control and exploit nature as endless resource. Klein rightly point out that "our economic system and our planetary system are now at war because with projected rates of carbon emission we are heading towards an environmental catastrophe that would irreparably damage the natural world, destroy lives, and destabilize human society. In the inter-connected natural system, a relatively small change in one element of climate can abrupt changes in the whole system.

The current integration of sustainability into the development framework is not very pragmatic and receptive to the needs of the future generations. Sustainability is not the combination of economics, social and environment, since it not possible for societal and economic systems to exist independently from the environment. For this reason, sustainability is when the natural law becomes the primary laws of economic and social development. It is not that the environmental consideration has to dominate the other disciplines in order to name it sustainability. All other disciplines are dependent in one form or another on the environment and nature. The current conceptualization of sustainability can't ensure equality or a balanced approach because they encounter forces i.e. social and economic development, are unequal in strength and type. The essence of natural laws is to ensure survival of nature. Protecting the environment must not be the only cry from the people, but the people must better protect themselves also from harming the environment.

The environment is governed by natural processes but the beings in it either function imperfectly or in some cases don't accept the nature as the prevailing force over everything. All beings are produced perfectly, but the physical and intelligible factors make them imperfect or unfit in a perfect nature. The seen and unseen forces in the human environment are composed of inborn qualities, doctrine, customs, traditions, and values that lack the basic recognition of ecosystem services. Since all humans live on this one planet and coexistence is critical for the sustainability of nature but huge contradictions in cultures and views about nature or weak perceptions, beliefs, and understanding of nature and its laws are harbingers of future chaos, curse and collapse of societies.

According to Richard Dawkins [2], the biological world does not make sense except in the light of evolution. For instance, "the vast majority of evaluation change is invisible to direct eye-witness observation" or most of it happened before we were born, and in any case it usually too slow to be seen during individual's lifetime. According to Dawkins "Biologist often make a distinction between the fact of evolution (all living things are cousins), and the theory of what drives it (they usually mean natural selection, and they may contrast it with rival theories such as Lamarck's theory of 'use and disuse' and the 'inheritance of acquired characteristics'). The point is that evolution takes a long time to realize and one's lifetime is relatively short. Over the course of one life, humans can't see the change over time of the evolution of a species.

Scientific acceptance requires deep thinking and understanding of the multifaceted functions and services of nature through logical demonstration of the case, issue, problem or subject. I call science the knowledge of facts. However, I also understand the challenges that scientific minds may go through to accept the facts. Fact is "something that has really occurred or is actually the case; something certainly known 
to be of this character; hence, a particular truth known by actual observation or authentic testimony, as opposed to what is merely inferred, or to a conjecture or fiction; a datum of experience, as distinguished from the conclusions that may be based upon it".

Humans as the higher being in the food web are yet to be reconnected naturally with the rest of the food hierarchy because these are all environmental aspects of one indissoluble process. However, it is true that in the nature, it is some combination, arrangement and organization of all living and non-living beings in the food web that result into further structures, functions, and categories. To treat them separately makes the natural food web forms disconnected that eventually produce continues changing conditions in the ecosystem or fear among beings for long term survival.

The statements are true in the current highly intolerable conditions in the world and the world requires a fundamental shift in the paradigm. National laws and institutions are seen as invasive and people tend to act in their own self-interest contrary to the common good when there are open-access resources. Unrestricted access to natural resources (land, air and water) generally results in overexploitation. This overexploitation, in turn, results in over consumption of the depleted natural resources and increased waste production. Government's primary responsibility is to define overexploitation and limit overexploitation in order to set rules to satisfy the efficiency criterion.

Looking at the exponential growth in the human needs and steady response of nature to human needs often creates situations where natural and human relations becomes broken, unpredictable and dangerous. For example, quality of the environment is compromised for short term gains and Kabul is a good example. This also creates the environment in which the potential of both the nature and people become locked. In such societies, common resources i.e. air, land, water and biodiversity or natural resources become the fundamental factors in defining values or wealth of a particular group or groups of people.

The society in transition to enlightenment period uses earth resources with the first come first serve basis. A transitional society is one in which yet the science is considered as an invader and the transformed society in which the science has been accepted. In a transitional society, the people think that if they don't use the resource, someone else will use the resource. In transformed societies, they must work to create balance between the supplier (natural environment) and user (Humans). How we bring these two societies into one indissoluble process is yet to be determined.

Conservatives education system or institutions considered the fundamental scientific knowledge and message that unlock human's enormous potential and open new ways for research, innovations, scientific discoveries absurd.

\section{What this all Mean to Afghanistan}

In Afghanistan, both the natural potential and cultural challenges are immense. Evidence suggests that resource abundant nations are less likely to experience rapid develop- ment. Potential exist in the nature and challenges exist in the people that make the development very expensive and dirty. Development and environmental sustainability are difficult paradigms to understand in a country like Afghanistan, but we must start somewhere. One appropriate point of departure is clarifying what we mean by development and environment. In conventional notion, development can be traced to the way that development is measured (GDP or NDP), but the natural capital often called the stock of environmentally provided assets, such as the soil, the atmosphere, the forest, wildlife, and water are not adjusted. We can deplete our soils, cut down our forests, and pollute our water, land and air resources, the resulting economic activity is treated as income, not as a decline in the endowment of natural capital. Not adjusting the natural capital, policy makers rely on misleading information and are more likely to undertake unsustainable development strategies.

Having no environmental standards, lack of integration of science into the decision making process, unbalanced development approach and political and social disintegration have led different societies in the past to collapse to different degrees and in somewhat different ways. The causes of collapse of great empires and societies were a combination of hostilities of nature and humans' ignorance. The environmental problems are all connected and to me a single environmental problem is actually a combined effect of other environmental problems. Water, air, and land as we know are connected. Hydrological cycles or other cycles are good examples of it. Nothing escapes the earth if we think in terms of cycles. All is balanced in natural system.

I will take the example of the water problem in the Kabul city to show to the policy makers and international community the greater risk to the livelihood of the people of Afghanistan. Seeing the natural potential of the country versus challenges in the culture and the ignorance of the government agencies have earned me criticism over the development of Afghanistan. If the government of Afghanistan is not willing to adapt according to the change happening in the environment and climate and does not engage with different ministries and donor agencies, Afghanistan won't be able to survive with dignity or solve the environmental problems. Thus, I am writing this paper from my personal perceptive, with experience of both environment and culture problems, and development realities.

I lived in one house in Kabul for more than ten years. I trained professionally as an environmentalist. Over the last ten, years, I have been noticing change in the air, land and water quality and quantity. I am not doing research using scientific approaches or presenting reliable data, but frequently ask communities about the changes we have been experiencing over the past years in the environment. I apply my limited comparative method or the natural experiment using logic to compare natural situations with respect to changes in the nature. I love nature and watching the variation in climate and enjoy living in my environment and value every service of the ecosystem.

I have a well for domestic use at my house, which taps 
into the underground aquifer. The water in the aquifer has been contaminated for a long time, but the rapid decline in the quantity of the well water has been a surprise and shock to me. A few days ago, my mother told me that the water pump is not working, and we have to change it. I called the people to fix it. When the technicians checked it, they found that the water level has declined. This rapid decline in the well for me was a complete surprise and shock because we need water, we can't live without it. The natural inclination for people facing this same problem is go deeper into the aquifer. This is what I also did. However, I know that this is the sign of a much larger problem and every negative sign in the natural system invokes new problems. This indicates the problem of increasing demand for decreasing water. We can't emigrate the whole of Kabul to another place. If this trend continues with no action to manage water supply in Kabul better, more likely doomsday scenario involving human apocalyptic collapse of the Kabul city. If this reasoning comes true, then the development has been creating new problems for the people of Kabul without resolving old ones. If we deplete the water resources, can we count on being able to substitute some new resources. Indeed, it is not in human power to substitute water. Better to think and act now before it becomes too late.

I am taking water as the example since water flows into our veins as air and flows in the ecosystem and connect everything with every other thing in the environment. Change in the water quality or quantity is the sign of changing shape and forms of the food web or it is one of the important elements for social, economic or natural evolution to take place. Water is one of the key elements of social, economic and environmental development has been following courses of variations and contamination in Afghanistan, particularly in the ancient city of Kabul. Population growth with no path of prescribed solutions of their problems, unsustainable practices that lead to environmental damage resulting into ground water shortage and contamination that result into drought, starvation, wars among too many people fighting for too few resources. This combined effect results in a society that has lost some of the environmental, political, economic and cultural complexity that it has developed at its peak. Change occurs when the enabling environment is no more feasible both in the natural and cultural form for the beings to survive. This change may have termed "evolution" over time and evolution is not always positive. Change tests the resilience of the people every day in this country and there is huge difference between resilience and adaptation.

The World Population Review [3] estimated that the population of Kabul in 2020 has been 4,21,532, nearly triple the population in the 1970s. Water quality in the city from the past many years has been deteriorating so much that drinking almost requires a prescription from a doctor. The issue of water contamination is complex and requires actions all the from the grass roots level up to the Presidential level. All actions must be put in sequence and people and science must be integrated into all development cycles in order to ensure both fair quality and quantity. It is important to note that water resources (both surface and ground water) are connected.
The water from the surface (runoff, snowmelt, precipitation) percolates down through the ground to aquifer and becomes water resources underground. The water flow on the surface is faster than the water flows underground, but they all move in the same directions due to the effects of gravity. There is no doubt about increasing demand for aquifer water: Kabul's continuing population explosion means more people drinking more water and flushing more toilets.

Expensive yet very dirty development is underway to fix a country and nation of which cultural fundamentals and environmental potentials are not yet fully understood. Reasons of dirty development and some of the areas that I think the Government of Afghanistan has not taken with due consideration of the environment and culture are given below:

1. Key elements of sustainable development or meaningful development of the $21^{\text {st }}$ century have not been presented and implemented with the due understanding of the government institutional capacities and culture of the people. I don't say that the polices or projects designed are not according to the principles of sustainable development. In fact, the policies or projects are developed by very knowledgeable/experienced people but the capacity of the executive organizations or agencies are not that good. Basics are left behind, but advanced are followed. Most of the policies in Afghanistan are developed by very fine and well experienced and qualified people for people whose true capacities of execution are very less advanced. Afghan society over the past decades has become more illogical. In society now, logic is either considered a sin or madness. Disciplines or subjects that develop societies or institutions using logic are being repressed and the disciplines or subjects that vitiate societies or institutions using no logic are being kept dominant. Camouflaging transformed societies' knowledge and thinking according to the natural make-up of the untransformed societies in the current circumstances are difficult for the government institutions and the local people to understand, accept and implement. Afghanistan must see natural laws as the foundation for the development and integrate the essence of sustainability into their cultural and religious ladders of growth and regrowth.

2. Legislation is important to put in place to protect and prevent people and economic activities from further degradation of the deplorable water resources in the country. Water Pollution Control Regulation or Act must be put in place to exercise some direct influence over what is currently a free asset. Similarly, the Water Quality Act must be placed to improve the process by establishing ambient water quality state in the city of which implementation becomes mandatory for the public and private sectors. I understand that the city is unplanned and environmental planning and implementation might not bring the desired results, doing something is better than nothing.

3. The government must start conducting investigations, research and surveys in the Kabul city or other cities and find the riskiest places (point and non point sources) to the groundwater bodies. The public sanitation system is 
worse, discharge into public sewer system is very bad in major parts of the capital city, septic tanks are open, markets are dirty, solid waste is transferred from one place to another place in the same environment, hospital waste is poorly handled and agricultural land is being converted into housing. All of these contribute to the polluting of water bodies. This is serious business that requires strong and in-depth scientific research, laws, planning processes and actions. Environment is free in this country and does not require payment of an indemnity (penalty). Whoever purposely pollutes water shall be obliged to pay an indemnity. Threats to drinking water security in the form of bioterrorism or other intentional acts intended to disrupt the provision of safe and reliable drinking water supply, particularly in schools, must face both civil and criminal penalties. This solution would probe new thinking in people since centuries people are used to free services of the environment with no responsibility.

4. Both municipal sewage system and public sewage system in the city are unplanned and the negative impacts of the systems must be identified, scoped, and evaluated. International partners or countries must donate resources or grants that not only generate jobs, but also work to build a way for the future to be built on. Transporting waste from one point of the city to another point in the city is not solution. Indian government donated waste collecting vehicles, which is also needed, but this is not the solution to the growing problem. The areas near the dump sites are sacrifice those and the people who live in proximity suffer deeply. Low-income communities are deliberately targeted to threats to hazardous waste landfills, incinerators, agricultural pesticides, sweatshops and polluting factories. This discrimination must be converted into environmental justice where all people have safe and quality environment. Environmental justice ensures that people have basic right to be free of toxic or otherwise hazardous environments. Communities at-risk must have right to the information or meaningful participation in the decision-making process. It is important to introduce new technologies for instance, waste water treatment plants, recycling of waste, water quality monitoring wells, and other technological solutions. Conversion of waste into money is possible through recycling, or conversion of waste into energy. Challenges always exist to embark on such great ideas. However, I see kids in the street collecting waste and selling them. It is already happening at a very small scale and could be studied, researched and presented to private sector.

5. In the environment, actions are easy to take, but seeing improvements takes time. We must understand this time lapse in action and reaction. Seeing today's depletion of the ground water table is the clear indication of the damage people inadvertently inflict on their environment. The water supply is seriously damaged and demand is exponentially growing. In such leaner equation, a small change in the climate (drought) could seriously impair human's resilience, adaptation capacity of the society, and increase fragility of the environment. Drought is a recurrent phe- nomenon in the country that linking with human's actions might not be right. In fact, climate may become hotter or colder, wetter or drier, or more or less variable between months or between years, because of changes in natural forces that drive climate and this natural process have nothing to do with humans. In Afghanistan, typical climate to which people have long been adapted, does not mean that the people have the knowledge and capacity to take maximum benefits from the natural resources without depleting of their environmental resources. The environmental resource-depleted society, particularly when the climate becomes drier, colder, hotter, wetter or more variable is on the brink of collapse. Environmental refugees are an example of it in the country. If a society hadn't already partly depleted its environmental resources, it might have survived the resource depletion caused by climate change.

6. Water quality and quantity are very much linked to every human on the earth and every surface that they dig in. Water deterioration is all happening due to improper balance of the environment, people and development. If the trend continuous with the same level of ignorance and lack of action against the same level of risk, it is very much predictable that the people and the government will face a disastrous situation in the near future. The people drill more wells into the same aquifer thus lowering its level, probably because no standards for drilling wells in houses are developed for Kabul or implemented and monitored. Laws, regulations or standards about domestic water currently are weak. Every new house owner drills lower than the water level of a neighbor's well. The damages are sequential and collateral. Aquifer recharge projects are underway, but the best solution could be to calculate how much domestic water use an aquifer could support, one would have to map the aquifer and to measure how rapidly water is flowing into it. These two elementary steps have not been completed for the Kabul City, the city of more than 5 Million.

7. In response, government agencies and particularly the National Environmental Protection Agency of the country is superbly focused on the environmental education and awareness. This temporary energy lost very soon. A subject that we have been testing since NEPA establishment with no change at all in the environmental status. Reasons exist why environmental education and awareness is not working in this country or in many other countries of the world. NEPA relies on a battery of consultant for environmental education and awareness only, it must begin to study the technologies of pollution, integrate science and research into national development plans, and must take into account the age of equipment and facilities, the engineering aspects of the application of various types of control techniques. This capacity to prepare appropriate scientific, administrative plans at NEPA doesn't exist and it is a must that NEPA work with the regional environmental bodies to understand their institutional set up, legislations, technologies and scientific approaches. This capacity can't be produced at NEPA through international partners. This 
needs government-to-government relationships and for it NEPA must establish continuous relationship with regional government environmental agencies.

It is fact that the environmental standards that Europe, USA or other developed nations can't be exercised here in Afghanistan. Environment is not a national priority, but it does not mean that interest in the subject does not exist. Politicians probably looking for practical reasons or comprehensive program to draw important distinctions between dirty development and somewhat good development. It won't feel good if a scientist in the future says to our kids that your ancestors were bad stewards of their environment, so they deserve to be dispossessed. In fact, the current generation faces it and the future generation may face it in a harsh and unbearable way. Kabul faces all of these challenges but there also are enormous opportunities. Respecting natural integrity and producing a gentle and ecologically wise population in the current uncertain and unpredictable circumstances is difficult but not impossible. Before presenting practical actions, it is good to think how to manage the environmental resources sustainably, and produce practical reasons over the years to prevent further degradation of the environment. It is difficult to get people to agree to exercise self-restraint in harvesting a shared resource, particularly where poverty level is above 40 percent of the total population. Similarly, we can't ignore the humans struggle for survival or rationalism and the broken links between the environment and development. Environmental problems that are hard to predict or manage today were surely much harder in the past. People now see the real change in their environment and understand that every action has equal reactions. Society's response in the form of traditional, indigenous and historical knowledge must be taken into consideration while preparing the response for the reactions. Other factors that also contribute to a society's responses depends on the political, economic, and social institutions an its cultural values. However, all the factors considerations into the preparation may take time.

8. Starting reforms (modernization) in urban areas have always produced unintended consequences for the state. History shows that reforms in the urban areas have not brought positive changes in the lives or ideologies of the people living in the rural areas. A country made of tribes and ethnic groups can't walk on the same path with the civilized world unless reforms are started from the rural areas. One of the critical pillars in reforms is to agree upon what do we mean by Science in Afghanistan. Science, as the knowledge of facts, in the current education and development paradigm in both urban and rural areas has paradoxical definitions. Science is the foundation of nation building and any nation that constantly ignore scientific thinking or methods will sow the same seed of ignore or history will repeat itself. Lack of scientific vision or a government not backed up by science will act illogically. Building scientific thinking or science backed up government in the current instable situation is difficult since war is the biggest monster, but the history of develop- ment shows that without scientific thinking and logic, all decision are meaningless, unsustainable or ineffective. Science makes good and rational humans that are what Afghanistan needs. Moving away from the facts won't change the facts, but one may deceive theirs self and their future generations.

9. And finally, why I call this development dirty development. If all the body is cleaned except the source of the dirt, the body is still dirty. This is equally applicable to the environment in the city of Kabul. Development that we see in the form of buildings or shopping mall, but without considering the social welfare or the positive externalities of the development, this development is dirty development. Government has been struggling to bring peace and stability to the country but as that happens, Afghanistan has to define and differentiate between dirty development, somewhat good development and sustainable development. I am pro-development, but there has to be thinking in the minds of the custodians and decision makers of this country to when and where would we establish nexus between development and the environment.

\section{Conclusion}

Big challenges mean big opportunities. Change is possible. Business as usual must be questioned since there is increased warning in the natural system (i.e. air, water and land) due principally to the unrestrained growth, dirty development, and environmental racism. Criticism over the discursive constructions that shape our view of nature and sources that constitute or construct our perception of what we consider to be natural or an environmental problem. Similarly, it is important to understand what environment is constituting of and what this responsibility mean for a National Environmental Protection Agency in the framework of sustainability or in the context of the present and future generations. There is not objective environment in the phenomenal world, no environment separates from the words we use to represent it. All associated set of cultural values nurtured as result of our nature must be viewed as reflection of reality not as deflection of reality. The escaping from negative impacts of environment due to the fact that technology or economic growth will reduce helps us in the future to me as deflection of reality. The arts of good citizenship or environmental activism must be taught to political leaders and citizens though available means of persuasion. Purposeful and consequential efforts to influence political environment, society's attitudes and behavior in Afghan society needs a combination of already accepted and adapted traditional and historical environmental friendly methods or approaches for setting some new directions.

How great civilizations fade away from the face of the earth is not because they did not protect the environment but because they did not protect themselves from the environment. Unfamiliarity with the changing environment brings their mighty power into dust. According to Jared Diamond [4] the four-factors, i.e environmental damage, climate change, hostile neighbors, and collapse of essential trading partners, may or may not prove significant in the collapse of a particular society, but the "fifth set of factors-the society's respons- 
es to its environmental problems-always proves significant". Example of such great empires include the ruins of the medieval Southeast Asian city of Angkor in modern Cambodia, Easter's Isolation or other Maya cities that are the most familiar examples of this now vanished urban model. The great empires have succeeded in establishing great cities, but eventually became defeated by the environmental problems. The greatest risk of all environmental problems was weak water management to cope with extreme weather swings between severe droughts and severe floods. In his words, many of them destroyed themselves by overexploiting or destroying their own resources, failure to anticipate future consequences, inability to read trends or see behind the phenomenon of "creeping normalcy", and rational bad behaviors. His words are totally reasonable and understandable that the kind of collapse experienced by many cultures and civilizations in the past could happen to modern-day societies. Jared Diamond very correctly predict the conditions for collapse in modern world: "Today, Just as in the past, countries that are environmentally stressed, overpopulated, or both, become at risk of getting politically stressed, and of their governments collapsing. When people are desperate, undernourished and without hope, they blame their governments, which they see as responsible for or unable to solve their problems. They try to emigrate at any cost. They fight each other over land. They kill each other. They start civil wars. They figure that they have nothing to lose, so they become terrorists, or they support or tolerate terrorism". State is no more dead, but living and evolving. Procrastination and these pressures together are enough for a country to undergo.

Afghanistan is not as strong as those empires, but so far have survived or struggling to survive. However, Afghanistan is living in the modern world. Thanks to a flood of recent information from aerial radar surveys, ground surveys, excavation, and tree-ring measurements that tell us about the past and from it can answer the unanswered questions of the future. Invaluable environmental and cultural resources of Afghanistan have the potentials to raise it from the dust. However, as said in the beginning untransformed societies are hesitant to accept science as the knowledge of truth. Fundamental questions to survival are embedded in science and it is important to understand the evolution not in the context of Darwinism, but evolution in the context of socio-economic and ecological survival. Evolution is not some linear phenom- ena but somewhat some dynamic phenomena that is composed of different environmental elements of which water is the most fundamental.

Similarly, the cultural and religious constraints are not letting people to freely and truly express their ideologies and follow their dreams and put pieces firmly and united. The progressive but meanwhile indecisive mental thoughts cannot challenge and change the enforced cultural and religious dictatorship. The Stockholm definition of Sustainable Development is somehow against the conventional thinking of the ordinary people who believe that living in this word is actually test of their faith for living in another world, not for their present or future generations.

The culture that Afghans have been talking about either does not exist anymore or does not fit in this century. The culture, progress, victories and other good things is merely now a history. We are proud of it and we should be. However, we do not want to go back to that era. There are certain elements in our culture that are pushing us to that era. Going back to that era is impossible because such an era does not exist anymore. The $U$ turn is actually a way to extinction. However, there is another era which is certain, possible, and exist. It is the era of competition, creativity, openness and accepting science. However, this era demands change. We cannot live in dreams. More than anytime, moves that pull out the veil of ignorance are important.

We are products of our environment and of dominant Afghan culture and ideology and we, as the product of this age, have to rebuild and reinvent the very idea of the collective, communal, the commons, the civil, and civic after so many year decades of war and neglect. Because what is underwhelming about Afghanistan is that Afghan can't break the Afghan rules.

\section{References}

1. Klein N (2014) This changes everything: Capitalism vs. the climate. First Simon \& Schuster trade paperback edition. Simon \& Schuster Paperbacks, New York.

2. Dawkins R (2009) The greatest show on earth: The evidence for evolution.

3. (2020) Kabul population 2020. World population review.

4. Diamond JM (2005) Collapse: How societies choose to fail or succeed. Penguin Group, New York, USA.

DOI: $10.36959 / 742 / 226$

Copyright: (C) 2020 Niazi S. This is an open-access article distributed under the terms of the Creative Commons Attribution License, which permits unrestricted use, distribution, and reproduction in any medium, provided the original author and source are credited. 